\title{
O Sensoriamento Remoto como Ferramenta Didática no Instituto Federal Farroupilha Campus Jaguari- RS
}

\author{
The Remote Sensing as a Teaching Tool at the Institute Federal Farroupilha \\ Campus Jaguari RS
}

\author{
Carlos Alberto da Fonseca Pires, Cristina Cippolat Limana
}

Departamento de Geociências, Universidade Federal de Santa Maria, UFSM, RS, Brasil.

\begin{abstract}
Resumo
Este estudo trata do uso das tecnologias na educação de nível profissional e tecnológico, com ênfase nas ferramentas do sensoriamento remoto. O objetivo geral da pesquisa foi realizar um diagnóstico sobre a utilização de tecnologias do Sensoriamento Remoto (SR), no ensino técnico, junto aos cursos técnicos em Agricultura, Informática, Vendas, Agroindústria e Administração, cursos esses ofertados pelo Instituto Federal Farroupilha Campus Jaguari- RS. Metodologicamente, o estudo iniciou com pesquisa bibliográfica para identificar trabalhos já desenvolvidos sobre SR na educação Profissional e Tecnológica; após, foram escolhidos o campo de pesquisa e o público-alvo. Depois disso, aplicou-se um questionário composto por duas partes, a primeira parte com a finalidade de identificar e a segunda parte teórica, com perguntas de conhecimentos específicos sobre SR. A etapa seguinte foi a de organizar os dados coletados e confeccionar tabelas e gráficos; a partir desses dados, procedeu-se uma análise argumentativa, alguns dos resultados obtidos revelaram que a maioria dos alunos é do Curso Técnico em Administração, do sexo feminino e que residem no município de Jaguari-RS. Aproximadamente metade da amostra diz nunca ter ouvido falar em SR, mas afirmam ter interesse nesse assunto e acreditam que o SR possa estar ligado, de alguma forma, com o seu curso técnico, ressaltando assim, a importância de um trabalho em conjunto com os alunos e professores, que vise abordar os conceitos e teorias sobre o SR conforme a realidade de cada curso.
\end{abstract}

Palavras-chave: Ensino Técnico; Sensoriamento Remoto; Educação.

\begin{abstract}
This study addresses the integration and use of technology in professional and technological education level, with emphasis on remote sensing tools. The overall objective of the research was to conduct a diagnosis of the use of Remote Sensing technology, technical education, with technical courses in Agriculture, Information Technology, Sales, Agribusiness and Administration courses offered by these Instituto Federal Farroupilha Campus Jaguari RS. Methodologically the study started with literature search to identify work already developed on Remote Sensing in Vocational and Technical Education; after the field research and the audience were chosen, we applied a questionnaire consisting of two parts, the first part in order to identify and the second theoretical part, with questions specific knowledge about Remote Sensing. The next step was to organize the data collected, confection tables and graphs; from these data, we proceeded to an argumentative analysis, some of the results showed that most students is the Technical Course in Management, female and living in the city of Jaguari-RS. Approximately half of the sample says he never heard of SR, but claim to have interest in this matter and believe that the SR can be connected in some way with its technical course, thus highlighting the importance of working together with students and teachers, aimed at addressing the concepts and theories of $S R$ as the reality of each course
\end{abstract}

Keywords: Technical Education; Remote Sensing; Education. 


\section{INTRODUÇÃO}

As constantes transformações tecnológicas que ocorreram na história da sociedade transformaram a vida e o comportamento do ser humano. A tecnologia existe porque o homem sempre procurou aprimorar meios de sobrevivência, que lhe garantisse melhorias na qualidade de vida.

Atualmente podemos afirmar que, ao passo que as tecnologias necessitam do conhecimento adquirido pelo homem, o homem também pode usufrui-la para adquirir conhecimento. Pensando por este lado, existem inúmeros conceitos e habilidades, que podem ser adquiridos utilizando-se das tecnologias; podemos citar, entre outros, as tecnologias do Sensoriamento Remoto - SR, que podem ser utilizadas em diversas áreas do conhecimento e também em sala de aula.

Conceitualmente, Novo (2010) diz que SR é a

Utilização conjunta de sensores, equipamentos para processamento de dados, equipamentos de transmissão de dados colocados a bordo de aeronaves, espaçonaves, ou outras plataformas, com o objetivo de estudar eventos, fenômenos e processos que ocorrem na superfície do planeta Terra a partir do registro e da análise das interações entre a radiação eletromagnética e as substâncias que o compõem em suas mais diversas manifestações. (NOVO, 2010, p.28)

O uso de novas tecnologias nas diferentes etapas da educação é um dos enfoques dados nos Parâmetros Curriculares Nacionais (1998), que na época de sua formulação, observavam a importância da utilização de todo tipo de tecnologia em sala de aula.

Florenzano (2007) afirma que a partir da análise e interpretação dos produtos do SR, podem ser articulados os conceitos de lugar, localização, interação homem/meio, região e movimento, trazendo dessa forma, a realidade local para a sala de aula, principalmente nos estudos sócio espaciais.

Sausen (2002) argumenta sobre a importância de se acrescentar as imagens de sensores remotos em sala de aula, pois para ela, é desta comunidade de estudantes que surgirá o cidadão do futuro, que deverá entender o relacionamento entre meioambiente e sociedade, para proteger e preservar a terra.

Sobre a utilização do sensoriamento remoto nas instituições de educação, Florenzano (2007) afirma que é importante o uso das novas tecnologias, pois estas se destacam da maioria dos recursos educacionais e possibilitam a extração de informações multidisciplinares, uma vez que os dados de uma única imagem podem ser utilizados para várias finalidades.

Com o SR em sala de aula, o educando tem a possibilidade de observar lugares e estudá-los com uma nova perspectiva e visão espacial, criando assim novas oportunidades de aprendizagem.

As imagens geradas pelos satélites de sensoriamento remoto são uma ferramenta para serem utilizadas como recurso em sala de aula, Sausen (2002) argumenta que estas, oferecem uma visão sinótica da área abrangida por cada uma delas, por permitirem a coleta de dados temporais de uma mesma área e por coletarem 
informações sobre feições na superfície terrestre em várias faixas do espectro eletromagnético.

Para acrescentar o SR nos currículos e nas salas de aulas, a escola deve inovar o ensino, buscando novas formas para superar a deficiente educação sendo mais inovadora do que tradicional, já que o indivíduo deve estar inserido no mundo das tecnologias para que não seja afastado da sociedade moderna, assim

(...) a utilização efetiva das tecnologias da informação e comunicação na escola
é uma condição essencial para inserção mais completa do cidadão nesta
sociedade de base tecnológica. A utilização das tecnologias, no mundo atual,
está fortemente inserida nessas exigências. Além disso, nunca houve tanta
informação e conhecimento disponíveis num espaço de tempo tão curto.
(PIMENTA, 2008, p.04)

O SR pode ser empregado como recurso didático não só com relação aos conteúdos curriculares das diferentes disciplinas em uso multidisciplinar, mas segundo Machado (2002), também nos estudos interdisciplinares, que integram todas as disciplinas em torno da análise do meio ambiente, como nos estudos do meio e em projetos de educação ambiental.

Dentro desse contexto, este trabalho traz como tema o uso de recursos do sensoriamento remoto, questionando-se: os alunos de cursos técnicos conhecem os recursos e as ferramentas do SR? E qual a visão destes estudantes sobre o possível uso do SR também em sua futura profissão?

Este trabalho foi desenvolvido no município de Jaguari, localizado na região centro-oeste do RS e teve como público-alvo alunos de cinco cursos técnicos do Instituto Federal Farroupilha Campus Jaguari - IFF Campus Jaguari, sendo eles: Téc. em Agricultura, Téc. em Informática, Téc. em Vendas, Téc. em Administração e Téc. em Agroindústria.

O IFF Campus Jaguari está localizado na Estrada do Chapadão, s/n, primeiro distrito do município de Jaguari, nas antigas instalações do Colégio Técnico Chapadão, como pode ser observado na Figura 1, encontrando-se, aproximadamente, a nove quilômetros da sede do município de Jaguari - RS. 


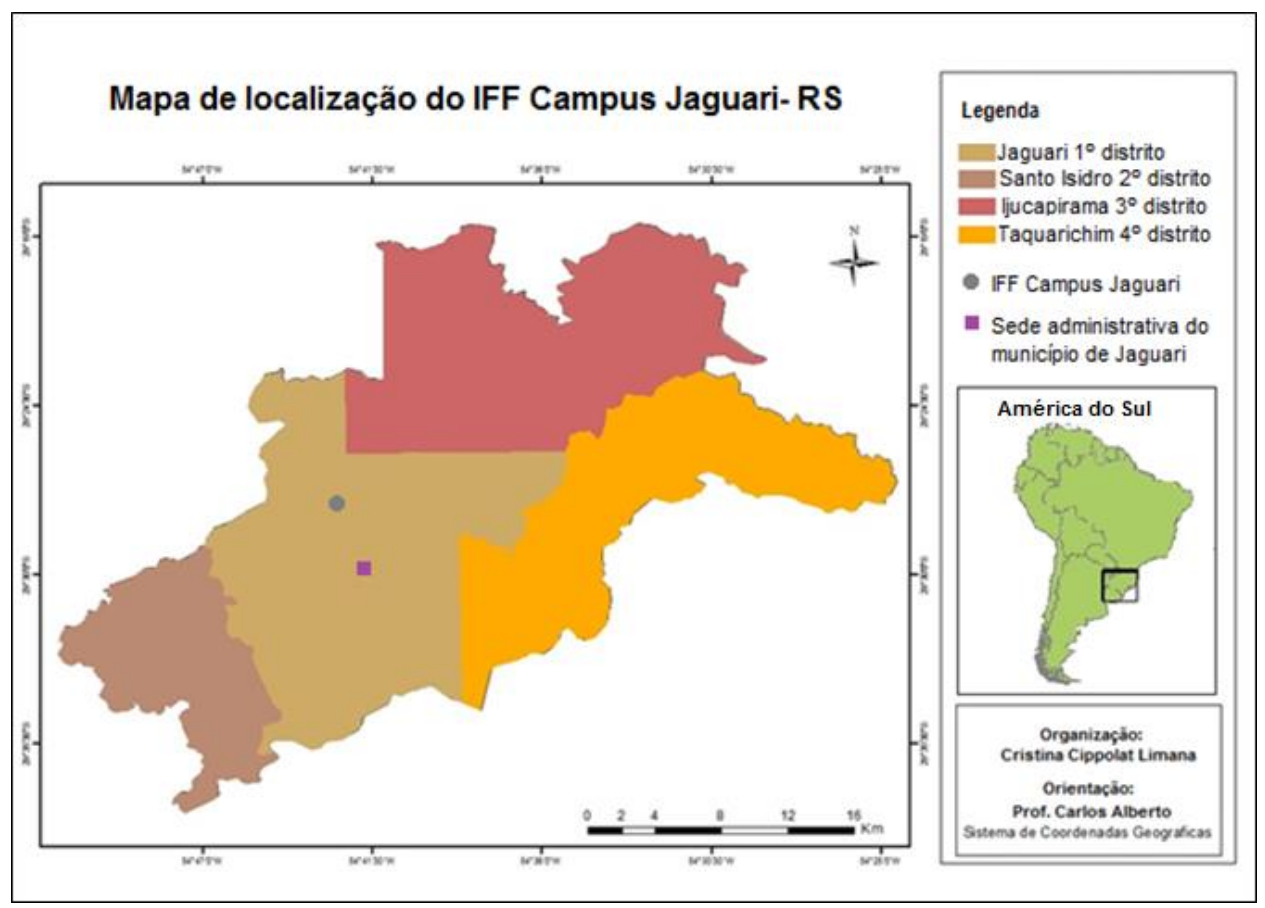

Figura 1- Localização do Instituto Federal Farroupilha Campus Jaguari.

\section{Org.: LIMANA, C.C}

O Campus Jaguari é relativamente novo, o mesmo iniciou suas atividades no dia 05 de dezembro de 2012 como campus independente, antes disso, era considerada Unidade Avançada do Instituto Federal Farroupilha de São Vicente do Sul.

Conforme o Relatório Final (2012) de implantação do Campus Jaguari, a justificativa para a implantação do mesmo no município é que

\footnotetext{
O Campus do Instituto Federal Farroupilha, em Jaguari, surge como alternativa para minimizar o principal problema socioeconômico da região: o esvaziamento da população da força de trabalho jovem da região. Quando a população jovem da região ( 15 a 19 anos) expande-se a $0,5 \%$ ao ano, no vale do Jaguari a mesma, decresce a $2 \%$ ao ano. (IFF, 2012, p.31)
}

Assim, o Campus torna-se uma alternativa para os moradores do município de Jaguari e da região Vale do Jaguari, a fim de que possam se qualificar sem sair da região, assim, fortalecendo-a e criando novas perspectivas profissionais.

Durante a pesquisa houve a participação de praticamente todos os alunos matriculados na instituição, somando um total de 152 alunos envolvidos diretamente e diversos professores e funcionários, que acompanharam as visitas e a aplicação dos questionários. Vale ressaltar que a comunidade escolar mostrou interesse na pesquisa, bem como no tema SR.

\section{METODOLOGIA}

A pesquisa apresentada caracteriza-se por ser descritiva e quantitativa, pois foi inspirada na interpretação, observação e na atribuição de significados e entendimentos aos dados coletados. 
$\mathrm{Na}$ pesquisa descritiva, é fundamental apresentar as propriedades de determinadas populações ou acontecimentos. Uma das características deste tipo de pesquisa esta na utilização de técnicas padronizadas de coleta de dados, como questionários e a observação sistemática, segundo Gil (2008),

\begin{abstract}
Dentre as pesquisas descritivas salientam-se aquelas que têm por objetivo estudar as características de um grupo: sua distribuição por idade, sexo procedência, nível de escolaridade, nível de renda, estado de saúde física e mental etc. Outras pesquisas deste tipo são as que se propõem estudar o nível de atendimento dos órgãos públicos de uma comunidade, as condições de habitação de seus habitantes, o índice de criminalidade que aí se registra etc. São incluídas neste grupo as pesquisas que têm por objetivo levantar as opiniões, atitudes e crenças de uma população. (GIL, 2008, p.28)
\end{abstract}

A pesquisa classifica-se, ainda como quantitativa, uma vez que se centra na objetividade, considerando que a realidade só pode ser compreendida com análise de dados, recolhidos com o auxílio de instrumentos imparciais, tais como os questionários. Sendo que, FONSECA (2002) argumenta que ao contrário das pesquisas qualitativas, os resultados da pesquisa quantitativa podem ser quantificados.

O procedimento metodológico para construção do referencial teórico do trabalho deu-se através de uma pesquisa bibliográfica desenvolvida a partir de pesquisas em livros, periódicos, dissertações, teses, sites da internet e legislações pertinentes com informações e reflexões relevantes aos objetivos propostos.

Após o levantamento bibliográfico, foi realizado o contato com o IFF Campus Jaguari, momento este que foram marcadas duas reuniões: a primeira para apresentar o projeto de pesquisa, e a segunda, para marcar as datas e horários para aplicação do questionário.

O questionário, instrumento utilizado para a coleta dos dados, foi separado em duas partes, a primeira foi estruturada com doze perguntas fechadas e de múltipla escolha, todas relacionadas com a identificação do público-alvo, contendo perguntas tais como, qual o curso, a escolaridade, residência, entre outras.

A segunda parte do questionário, de conteúdo específico, contou com oito questões de múltipla escolha e uma pergunta dissertativa, para que o aluno pudesse dar seu parecer sobre o projeto. Todas as questões do questionário tinham como base, conceitos sobre SR e os alunos deveriam responder as questões conforme conhecimentos prévios.

Os questionários foram todos aplicados conforme data marcada em reunião, nas próprias salas de aula. Para todos os cursos foi utilizado o mesmo modo de aplicação, com apresentação inicial da pesquisa, entrega dos questionários e no final explicação e tira dúvidas sobre o tema. $\mathrm{O}$ número total de questionários respondidos foi de 152 (cento e cinquenta e dois).

Para a análise, foram sistematizados os dados, a partir da confecção de gráficos com o software Excel 2010, com base nas tabelas de dados coletados junto às turmas do ensino técnico do IFF Campus Jaguari. Os resultados obtidos serviram como base para confecção de gráficos e histogramas. 


\section{RESULTADOS}

O maior número de questionários respondidos foi do curso de Téc. em Administração, turmas essas do turno da tarde. Vale destacar que esse é o único curso do IFF Campus Jaguari que tem duas turmas (turma 1 e 2) e no momento da aplicação do questionário, ambas eram as mais novas da instituição, apresentando assim um número elevado de alunos, se comparado aos demais cursos.

O menor número de questionários respondidos foram nos cursos Téc. em Vendas, Agricultura e Informática, respectivamente. O curso Téc. em Vendas é oferecido na modalidade PROEJA (Programa Nacional de Integração da Educação Profissional com a Educação Básica na Modalidade de Educação de Jovens e Adultos), no turno da noite. Já os cursos de Téc. Agricultura e Téc. Informática são da modalidade Integrada ao Ensino médio, ambos no turno da tarde.

Todos os alunos que responderam os questionários, integrantes da modalidade Integrada ao Ensino Médio, realizam aulas referentes aos seus cursos técnicos no IFF Campus Jaguari e o Ensino Médio em outras instituições de ensino, em sua maioria, em escolas estaduais da região.

Depois de analisados os gráficos, pode se constatar que aproximadamente metade da amostra diz nunca ter ouvido falar em SR, mas afirmam ter interesse nesse assunto e acreditam que o SR possa estar ligado de alguma forma com o seu curso técnico, ressaltando assim, a importância de um trabalho em conjunto com os alunos e professores, que vise abordar os conceitos e teorias sobre o SR conforme a realidade de cada curso.

Uma das primeiras perguntas era sobre a residência dos alunos envolvidos. Pode se observar que a maioria reside no município de Jaguari; foram 92 alunos, entre os 152, que declararam residir no município de Jaguari, município em que está instalado o IFF Campus Jaguari. Em segundo lugar temos o município de Nova Esperança do Sul com 43 alunos, em terceiro, Santiago, com 16 alunos e por último o município de Jari com apenas um aluno.

A próxima pergunta "Você já ouviu falar em SR?" tinha apenas duas alternativas: sim e não. A mesma revelou que apenas pouco mais da metade dos alunos já ouviram, alguma vez, o termo Sensoriamento Remoto, como pode ser observado na Figura 2. 


\section{Você já ouviu falar em Sensoriamento Remoto?}

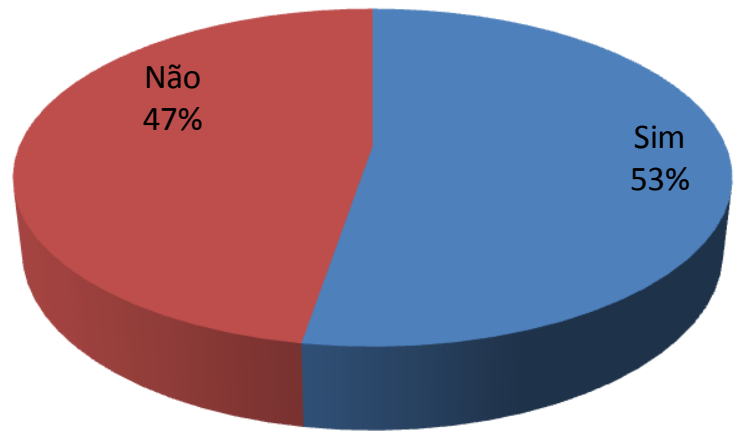

Figura 2 - Resultado da pergunta "Você já ouviu falar em Sensoriamento Remoto?"

A grande maioria dos alunos que disseram ter ouvido falar em SR eram respectivamente dos cursos de Agricultura e de Informática, mostrando uma relação mais estreita entre estes cursos e o tema central da pesquisa.

Seguindo nas perguntas, temos a questão "Quando alguém fala em Sensoriamento Remoto, você lembra:"; os alunos poderiam escolher uma entre as seguintes alternativas: imagens de satélite; computadores e tecnologias; espectro eletromagnético; fotografias aéreas; sensores; foguetes; universo; e outras. Os resultados são representados pela Figura 3.

\section{Sensoriamento Remoto remete à:}
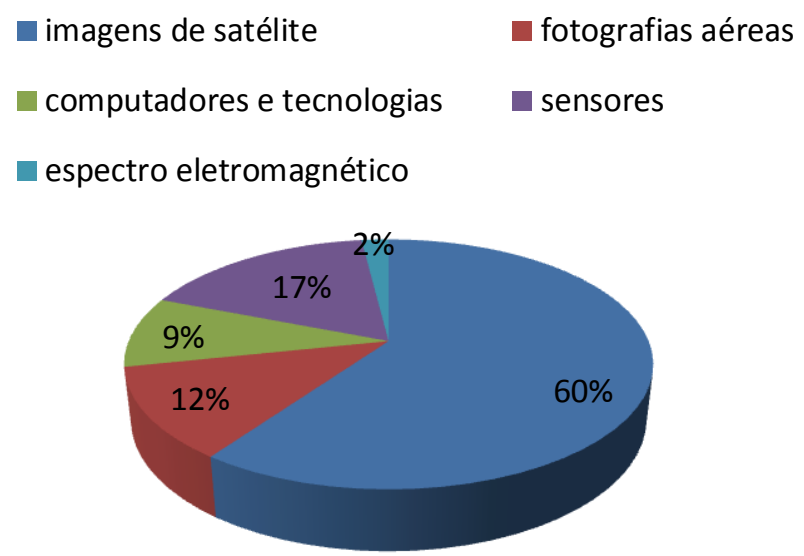

Figura 3 - Resultado da pergunta "Quando alguém fala em Sensoriamento Remoto, você lembra:". 
Com $60 \%$ das respostas, os alunos disseram lembrar, primeiramente, nas imagens de satélite, os demais alunos se dividiram, marcando uma ou outra alternativa, mas nenhuma com resultado muito expressivo.

Na Figura 4, temos a representação da importância do SR no processo de aprendizagem, conforme os estudantes envolvidos. Os resultados mostram que $92 \%$ acreditam que as imagens de satélite podem em algum momento auxiliar na aprendizagem. Apenas 3\% creem que imagens de satélite não contribuem com a aprendizagem e $5 \%$ dos entrevistados se mostraram indiferentes.

\section{Imagens de satélites podem auxiliar na sua aprendizagem?}

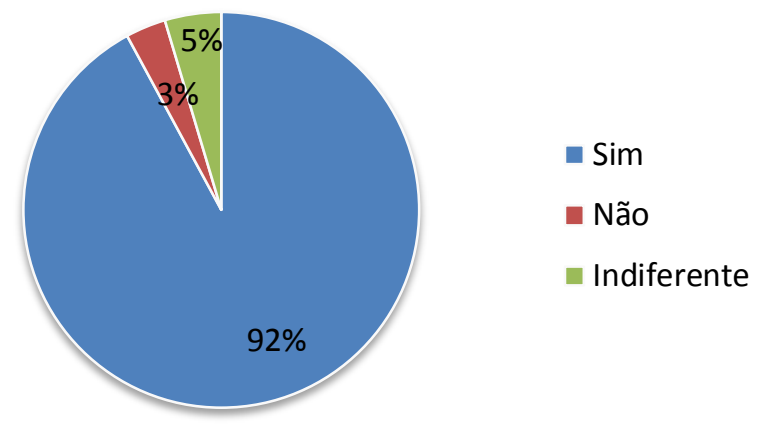

Figura 4 - Resultado da pergunta "Você acredita que o uso de imagens de satélites, pode de alguma forma, auxiliar no aprendizado?"

Pode-se observar que a maioria dos alunos acredita que a utilização de imagens de satélite e consequentemente outras ferramentas didáticas para a explicação de um conteúdo é, não só valida, como necessária. Devemos considerar que para o aluno, o "novo", ou seja, aquele conceito ou recurso didático, que está fora dos conteúdos programados em seu curso, também é importante e pode contribuir para o aprendizado.

Vale ainda ressaltar que a busca por novas formas de ensinar e de envolver o aluno no processo ensino-aprendizagem, ocorre em todas as etapas do ensino, isso porque já é senso comum dizer que recursos didáticos, sejam lá quais forem, favorecem a participação do estudante em sala de aula, tornando o ambiente de aprendizagem mais atraente e com uma função melhor definida diante a sociedade.

A Figura 5 apresenta as respostas para a pergunta "Para você o que é Sensoriamento Remoto?". Boa parcela dos estudantes, ou seja, mais de oitenta alunos têm ideia que o SR é um conjunto de imagens de satélite e fotografias aéreas. Em segundo lugar temos a resposta "uma técnica de obtenção de imagens da superfície terrestre", com mais de trinta respostas. 


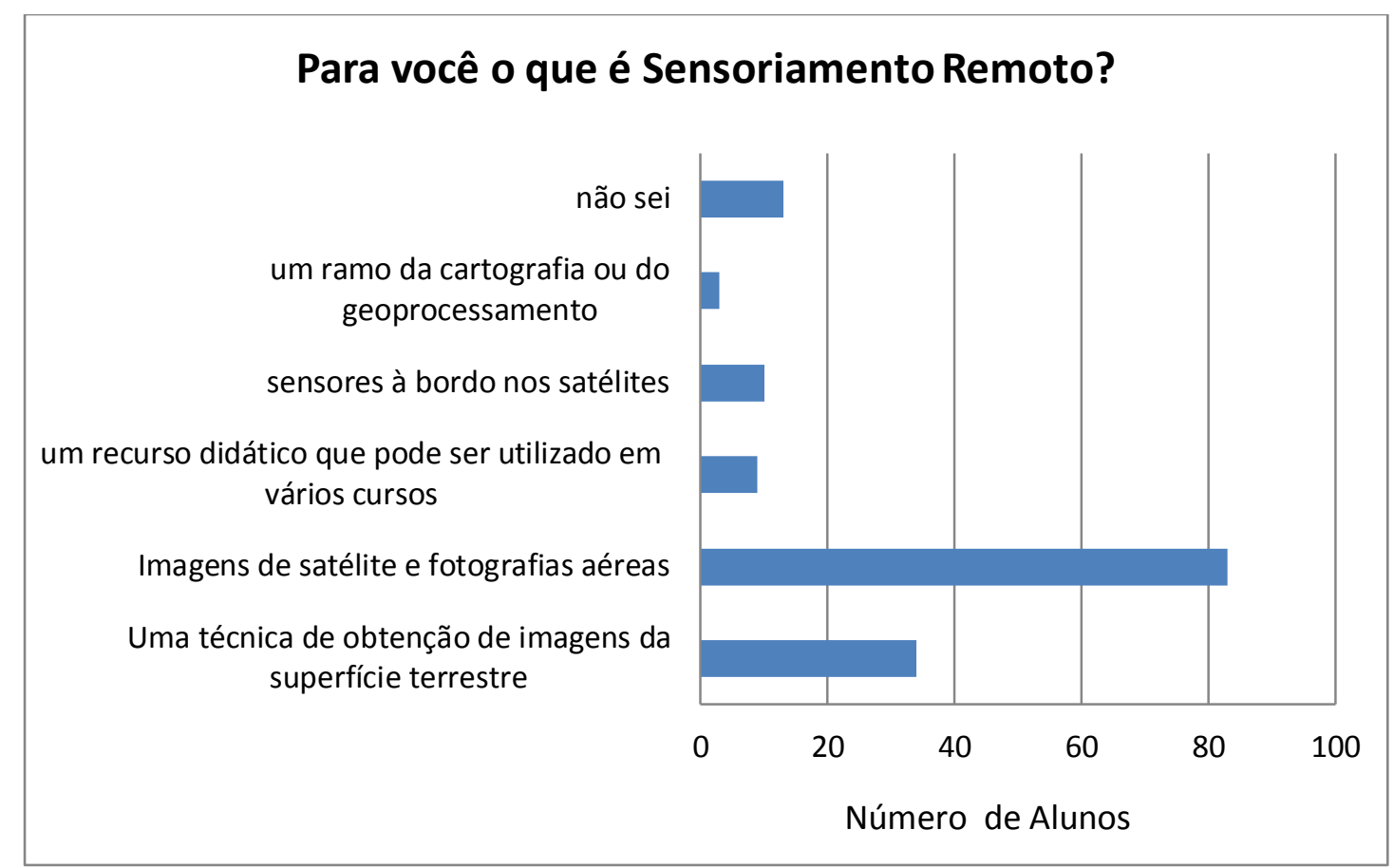

Figura 5 - Respostas referentes à pergunta "Para você o que é SR?"

Enquanto apenas 13 estudantes responderam "não sei" na questão apresentada na Figura 5, assumindo que realmente não sabem o que é SR, os resultados obtidos até então, demostram que o público-alvo não domina teoricamente o SR, mas o conhece empiricamente e sabe que este recurso pode ser utilizado, de alguma forma, em seus cursos, como pode ser observado no próximo gráfico.

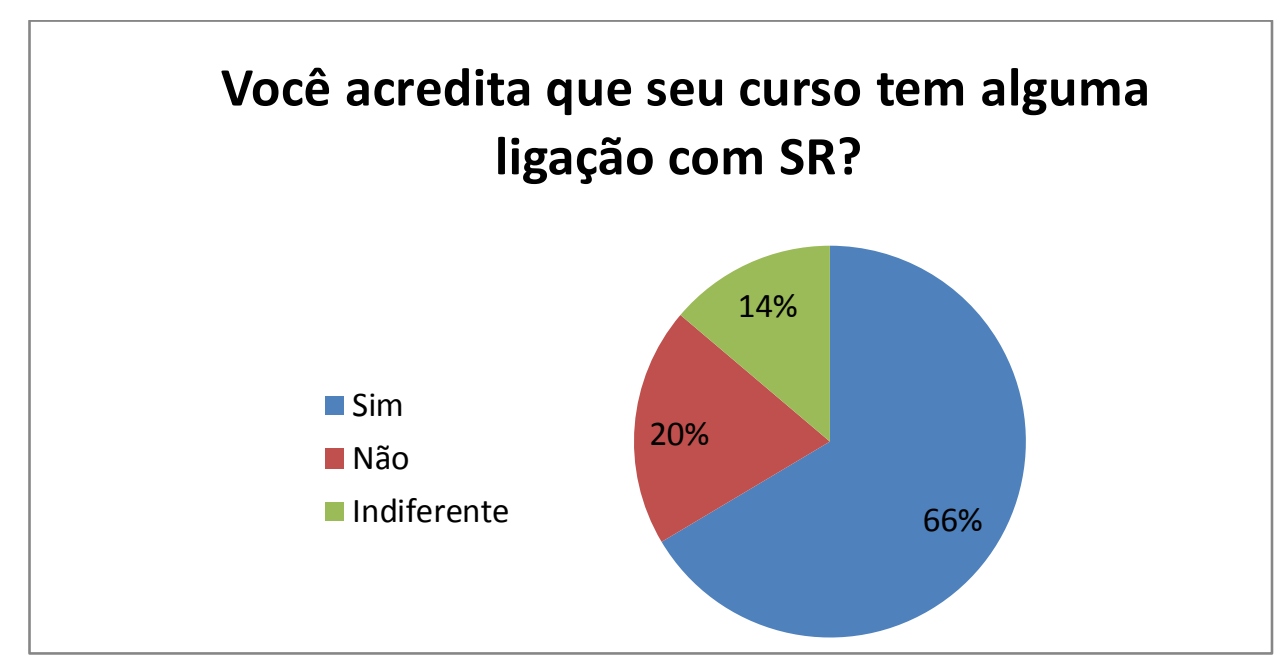

Figura 6 - Respostas referentes à pergunta "Você acredita que seu curso técnico tem alguma ligação prática com as tecnologias do SR?"

Podemos observar na Figura 6, que pouco mais da metade, ou seja, 66\% dos alunos acreditam que seu curso tem sim alguma ligação prática com as tecnologias do SR. 
No entanto $20 \%$, cerca de 30 alunos, não acreditam que as tecnologias do SR possam estar ligadas com seu curso técnico e 14\% são indiferentes. Estes últimos números, juntamente com as respostas das demais questões do questionário, provam que existem estudantes que ainda não tiveram oportunidade de conhecer o SR, seja em sala de aula ou fora dela. Assim, se faz necessário um novo trabalho com alunos e também professores, a fim de colocar os principais conceitos sobre o SR, incentivandoos a utilizar o SR como uma ferramenta didática em cada um dos cinco cursos técnicos.

\section{CONSIDERAÇÕES FINAIS}

Durante todo o percurso deste trabalho, as principais indagações foram: os alunos dos cursos técnicos do IFF Campus Jaguari conhecem os recursos e as ferramentas do SR? E qual a visão desses estudantes sobre o possível uso do SR também em sua futura profissão?

As avaliações feitas junto aos cento e cinquenta e dois alunos participantes da pesquisa revelam que a maioria dos alunos é do Curso Tec. em Administração, do sexo feminino e que residem no município de Jaguari, aproximadamente metade da amostra diz nunca ter ouvido falar em SR, afirmam ter interesse neste assunto e acreditam que o SR possa estar ligado, de alguma forma, com o seu curso técnico e consequentemente com sua futura profissão.

Os cursos que se destacaram, em relação às respostas dos questionários, foram Tec. em Agricultura e Informática, respectivamente, demostrando que de fato já tiveram contato com ferramentas didáticas sobre SR em seus cursos.

Pode se dizer que no geral, os alunos desta amostragem, conhecem pouco da teoria que envolve o SR e que é pertinente um futuro estudo ou projeto no qual se objetive trabalhar estas carências teóricas e conceituais de acordo com a realidade curricular de cada curso técnico.

\section{REFERÊNCIAS}

BRASIL. Secretaria de Educação Fundamental. Parâmetros curriculares nacionais: Geografia. Brasília: MEC/SEF, 1998.

FLOREZANO, T. G. Imagens de Satélite para Estudos Ambientais. Ed. oficina de texto. São Paulo, 2007.

FONSECA, J. J. S. Metodologia da pesquisa científica. Apostila, Fortaleza: UEC, 2002.

GIL, A.C. Métodos e técnicas de Pesquisa Social. Ed. Atlas, São Paulo, 2008.

INSTITUTO FEDERAL DE EDUCAÇÃO FARROUPILHA. Implantação do Campus Jaguari Relatório Final Jaguari, 2012. Disponível em: 
<http://www.ja.iffarroupilha.edu.br/site/midias/arquivos/20125251426374061_relatorio _iff_jaguari_-_ate_120.pdf > . Acesso em: $10 \mathrm{de}$ fev. de 2014.

MACHADO, M.C. O sensoriamento remoto na educação. In: FLORENZANO, T.G. Imagens de satélite para estudos ambientais. São Paulo: Oficina de Textos, 2002.

NOVO, E. M. L. de M. Sensoriamento remoto: princípios e aplicações, 4. ed. São Paulo: Blucher, 2010.

PIMENTA, I.C.D. O Professor PDE e os Desafios da Escola Pública Paranaense: Produção Didático-Pedagógica. Paraná, 2008.

SAUSEN, T.M. Projeto Educa Serelll: elaboração de carta imagem para o ensino de sensoriamento remoto: utilização de cartas imagens- CBERS como recurso didático em sala de aula. In: Capítulo 13, INPE, SP, 2002. 